\title{
Smoking, alcohol, and substance use and rates of quitting during pregnancy: is it hard to quit?
}

\author{
This article was published in the following Dove Press journal: \\ International Journal of Women's Health \\ 5 October 2016 \\ Number of times this article has been viewed
}

\author{
Ahmet Bulent Yazici' \\ Hilal Uslu Yuvaci² \\ Esra Yazici ${ }^{3}$ \\ Ebru Halimoglu Caliskan ${ }^{4}$ \\ Arif Serhan Cevrioglu ${ }^{2}$ \\ Atila $\mathrm{Erol}^{3}$ \\ 'Department of Psychiatry, Training \\ and Research Hospital, ${ }^{2}$ Faculty of \\ Medicine, Department of Obstetrics \\ and Gynaecology, ${ }^{3}$ Faculty of \\ Medicine, Department of Psychiatry, \\ ${ }^{4}$ Department of Obstetrics and \\ Gynaecology, Training and Research \\ Hospital, Sakarya University, \\ Sakarya, Turkey
}

Background: Alcohol and substance use is a major health challenge in Turkey, as it is worldwide. Recently, there has been a rapid increase in the number of females using substances and although usage tends to reduce during pregnancy, it is of critical importance to determine its exact level as substance use negatively impacts on the health of both the mother and infant.

Aim: The aim of the present study was to investigate the frequency of smoking, alcohol, and substance use, and quitting rates during pregnancy.

Method: This study was conducted on pregnant females in Sakarya, Turkey. A total of 1,082 consecutively presenting females who agreed to participate in the study were evaluated. The study team prepared a sociodemographic data form and adapted the "Introduction" section, derived from the Addiction Profile Index, to cover substance use during pregnancy.

Results: The substances most frequently used by pregnant females in their previous pregnancies and current pregnancies were cigarettes/tobacco products ( $11 \%$ and $11.8 \%$, respectively), alcohol ( $0.6 \%$ and $0.4 \%$, respectively), and rarely, synthetic cannabinoids $(0.3 \%$ and $0.2 \%$, respectively). Daily tobacco smokers continued to smoke during pregnancy, with a rate of $42.5 \%$. Based on research into predictors of smoking (cigarettes) in pregnancy, a correlation was found between lifetime smoking and smoking during a previous pregnancy. A similar link was found with respect to alcohol.

Conclusion: Cigarettes are the most frequently used substance in pregnancy, and to a lesser extent, alcohol and synthetic cannabinoids, also considered to be risky substances. A high incidence of smoking regularly during pregnancy was found in daily smokers. It is recommended that physicians should sensitively ask pregnant females presenting at clinics about all forms of substance use, including alcohol and synthetic cannabinoids, and to include such questions in their routine enquiries.

Keywords: perinatal, psychiatry, addiction, cessation, women, mental, health

\section{Introduction}

Smoking, alcohol, and substance use is a major health challenge in Turkey and worldwide. ${ }^{1-3}$ Studies in which the frequency of substance use was assessed have been conducted on a number of population groups in several Turkish cities. ${ }^{1,4,5}$ Although substance use and addiction are observed less commonly in females than in males in global studies, it is of concern that substance use has been identified as prevalent in females of childbearing age (15-44 years) ${ }^{6,7}$ The prevalence of smoking, drinking, and substance use is known to vary, based on factors such as ethnicity, culture, and religious beliefs. ${ }^{8,9}$ In particular, while substance use in females in Turkey is lower than that reported at global level, it is comparatively higher in young females of childbearing age. ${ }^{1}$

According to the 2013 National Survey on Drug Use and Health (USA), 11.4\% of nonpregnant females and $5.4 \%$ of pregnant females use illicit drugs, drink alcohol
Correspondence: Esra Yazici Department of Psychiatry, Faculty of Medicine, Sakarya University, 54000, Korucuk, Adapazarı, Sakarya, Turkey Tel +90533 3870679

Fax +902642552105

Email dresrayazici@yahoo.com 
(55.4\% and $9.4 \%$, respectively), and smoke cigarettes (24\% and $15.4 \%$, respectively). ${ }^{8}$ The most frequently used legal substances in pregnancy were found to be cigarettes $(10 \%-23 \%)$ and alcohol (10\%-12\%) in Canada and the USA, while marijuana (5\%) and cocaine were determined to be the most prevalent illegal substances. ${ }^{10,11}$ Polysubstance use was reported to be as high as $50 \%$ in some studies. ${ }^{12,13}$

While cigarette use in pregnancy has been investigated to some extent by clinicians, alcohol and substance use has generally escaped attention. Based on Turkish Statistical Institute (TSI) health research data from 2012, 10.8\% of females aged $\geq 15$ years smoked every day, $12.7 \%$ had smoked at least once by this age, $3.8 \%$ drank alcohol regularly, and $92 \%$ had never consumed alcohol in their lives. The rates of drinking and smoking in females were found to be higher in urban areas. ${ }^{14}$ The prevalence of smoking during pregnancy was found to vary from $3 \%$ to $37 \%$ in Turkish studies. ${ }^{15}$ Nationwide studies on smoking, alcohol, and the use of other substances have not been carried out in Turkey. ${ }^{15}$

It has been demonstrated in studies on pregnant females that while the frequency of substance use decreases at other times, it is still a significant health burden. Smoking during pregnancy is associated with poor birth outcomes, such as low birthweight, intrauterine growth restriction, placental abruption, and placenta previa. ${ }^{16}$ Alcohol ingested during pregnancy can have a deleterious impact on the developing fetus and includes fetal alcohol syndrome and alcohol-related effects. ${ }^{17}$ Illicit drug use in pregnancy impacts negatively on the fetus and is associated with higher rates of prematurity, intrauterine growth restriction, placental abruption, neonatal withdrawal syndrome, ${ }^{18}$ and cognitive impairment. ${ }^{19}$

Substance use in pregnancy has escaped the attention of most psychiatrists and gynecologists, despite having such a harmful effect. It is expected that most pregnant females who use harmful substances are motivated to quit when pregnant because they have a fetus. However, data on this subject are limited, but it has been reported in previous studies that it is not easy to readily quit smoking and other substances. ${ }^{20,21}$

The purpose of the present study was to investigate the frequency of smoking, alcohol, and substance use and quitting rates during pregnancy.

\section{Method}

This study was conducted on pregnant females, aged 18-45 years, presenting at the Outpatient Clinic of Obstetrics and Gynaecology, Sakarya University Training and Research Hospital, Turkey, and who agreed to participate therein. Consecutively, presenting pregnant females (8-40 weeks) admitted to our outpatient clinic for the first time between June and September 2015 (1,400 females) were asked to participate in the study. Study participants $(1,082)$ with adequate intellectual-cognitive capacity to form a clinical impression and who were capable of understanding and completing a set of questions pertaining to the scale were included in the study.

\section{Study instruments}

A sociodemographic data form, prepared by the study team, was used. The Addiction Profile Index, ${ }^{22}$ containing questions on sociodemographic data and the use and frequency of substance use, was adapted to incorporate information on substance use during pregnancy. The original form contained questions on the frequency of substance use over the last few preceding years. The adapted form contained questions on alcohol and substance use during the last and previous pregnancies. The form included five Likert categories according to the period investigated, as follows:

- Never.

- At least once or twice.

- Monthly (one to three times/month).

- Weekly (at least once/week).

- Daily (at least once/day).

Questions on a decoy substance, relactin, were also included and responses thereto were used to determine and predict the reliability of participants' answers. ${ }^{5}$ The original Addiction Profile Index form is a self-reporting scale consisting of 37 questions and five subscales covering substance use characteristics, addiction diagnosis criteria, the effect of substance use on a person's life, craving for a substance, and motivation to quit. In an analysis of the form's reliability, the Cronbach's alpha coefficient for the entire scale was found to be 0.89 , while the subscale coefficients were determined to be between 0.63 and 0.86 . The scores for the substance correlation coefficients were between 0.42 and 0.89 for the entire scale. The Spearman-Brown prediction formula was used to determine the split-half correlation, which was found to be 0.83 .

\section{Statistical analysis}

The data were analyzed using Statistical Package for the Social Sciences (SPSS) version 17.0 (SPSS Inc., Chicago, IL, USA). Rates and frequencies are given in percentages. Likert-type answers to the scale had to be selected, ranging from 0 to 4 . The scores were evaluated as ordinal variables. The normally distributed values were evaluated using a histogram and a test to measure skewness and kurtosis. Variables that were not normally distributed were analyzed using the Wilcoxon 
signed-rank sum test. Categorical data analysis was performed using the chi-square test. Linear regression analysis was conducted to determine predictors of substance and alcohol use. Statistical level of significance was set as $P=0.05$.

\section{Ethical approval}

All procedures performed in studies involving human participants were conducted in accordance with the ethical standards of the institutional and/or national research committee and the 1964 World Medical Association Helsinki Declaration and its later amendments.

Approval to conduct the study was obtained from the Ethics Committee of the Faculty of Medicine of Sakarya University, Turkey.

Written informed consent was obtained from all the participants who took part in the study.

\section{Results}

This study was conducted on 1,082 pregnant females being monitored at the outpatient clinic (obstetrics and gynecology) at the hospital. The age of females ranged from 18 to 45 years, with an average age of $28.35 \pm 5.52$ years.

A quarter of the females $(n=253,23.4 \%)$ were elementary school graduates and literate, 223 (20.6\%) were middle school graduates, 338 (31.2\%) were high school (and equivalent) graduates, and 268 were (24.8\%) university graduates. The majority of the patients $(n=1,077,99.5 \%)$ were married. The median number of pregnancies was 2 (with a range of 1-8) and the median number of children was 1 (with a range of 0-6).

The study respondents admitted using alcohol, tobacco, and synthetic cannabinoids during their current and previous pregnancies and on a lifelong basis, but denied using marijuana, "ecstasy", heroin, cocaine, "crack", benzodiazepine, volatile substances, and amphetamine derivatives. None of the females reported using relactin. The results are provided in Table 1.

\section{The ability of tobacco smokers to quit during the current pregnancy}

The ability of tobacco smokers to quit was evaluated after dividing them into two groups of daily smokers and those who smoked less frequently. Nearly half of the daily smokers $(42.5 \%)$ did not quit smoking during their current pregnancy. The corresponding rate in the second group was 7.9\% (Figures 1 and 2).

A comparison was made between the use of alcohol and substances during pregnancy and that over a lifetime. The use of tobacco was found to be significantly lower in previous pregnancies $(z=-11,865, P \leq 0.001)$ and in the current

Table I Alcohol and substance use lifelong and during to pregnancy periods

\begin{tabular}{|c|c|c|c|c|}
\hline & Alcohol & Other, SC** & Cigarettes & Various drugs \\
\hline \multicolumn{5}{|l|}{ Lifelong use* } \\
\hline Never & $96.1(1,040)$ & $99(1,077)$ & $67.2(727)$ & $99.9(1,081)$ \\
\hline Only once or twice & $\mathrm{I} .85(20)$ & $0.2(2)$ & $4.3(47)$ & $0.1(1)$ \\
\hline Monthly one to three times & I.I (12) & $0(0)$ & $2.2(23)$ & $0(0)$ \\
\hline Weekly one to five times & $0.185(2)$ & $0(0)$ & $2.8(31)$ & $0(0)$ \\
\hline Daily & $0.73(8)$ & $0.3(3)$ & $23.4(254)$ & $0(0)$ \\
\hline Total positive & $3.9(42)$ & $0.5(5)$ & 34.1 (355) & $0.1(1)$ \\
\hline Total \% (number) & $100(1,082)$ & $100(1,082)$ & $100(1,082)$ & $100(1,082)$ \\
\hline \multicolumn{5}{|l|}{ Previous pregnancies* } \\
\hline Never & $99.4(663)$ & $99.7(665)$ & $88.9(593)$ & \\
\hline Only once or twice & $0.15(1)$ & $0.15(1)$ & $1.3(9)$ & \\
\hline Monthly one to three times & $0.15(I)$ & $0(0)$ & $0.6(4)$ & \\
\hline Weekly one to five times & $0(0)$ & $0(0)$ & $1.6(11)$ & \\
\hline Daily & $0.3(2)$ & $0.15(1)$ & $7.5(50)$ & \\
\hline Total positive & $0.6(4)$ & $0.3(2)$ & $11.0(74)$ & \\
\hline Total \% (number) & $100(667 * * *)$ & $100(667 * * *)$ & $100(667 * * *)$ & \\
\hline \multicolumn{5}{|l|}{ Current pregnancy* } \\
\hline Never & $99.6(1,078)$ & $99.8(1,080)$ & $89.2(965)$ & \\
\hline Only once or twice & $0(0)$ & $0(0)$ & $\mathrm{I} .5(\mathrm{I} 6)$ & \\
\hline Monthly one to three times & $0(0)$ & $0(0)$ & $0.8(9)$ & \\
\hline Weekly one to five times & $0(0)$ & $0(0)$ & $2.1(23)$ & \\
\hline Daily & $0.4(4)$ & $0.2(2)$ & $6.4(69)$ & \\
\hline Total positive & $0.4(4)$ & $0.2(2)$ & $\mathrm{I} I .8(\mathrm{I} \mid 7)$ & \\
\hline Total \% (number) & $100(1,082)$ & $100(1,082)$ & $100(1,082)$ & \\
\hline
\end{tabular}

Notes: *Values are given as \% (n). **Synthetic cannabinoids. ***Calculation was made for the sample with multiparas. Abbreviation: SC, synthetic cannabinoids. 


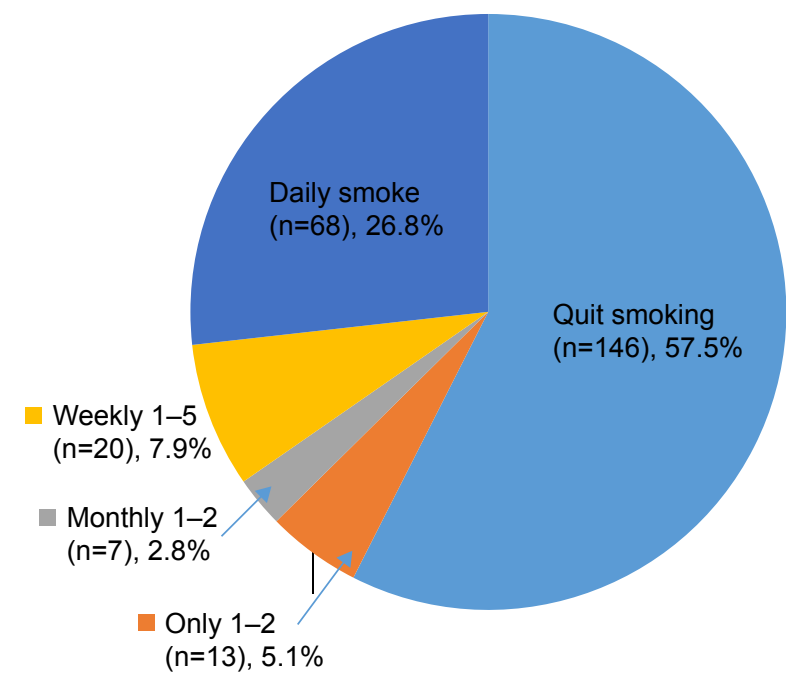

Figure I Quitting rate of daily smokers during pregnancy.

pregnancy $(z=-14,820, P \leq 0.001)$ than that over a lifetime (Wilcoxon signed-rank sum test).

The same was found with respect to alcohol use in previous pregnancies $(z=-3,901 ; P \leq 0.001)$ and in the current pregnancy $(z=-5,103, P \leq 0.001)$ (Wilcoxon signed-rank sum test). Half of the participants who consumed alcohol daily continued to do so during their pregnancy. More than half of the respondents $(n=2,66.6 \%)$ who reported using synthetic cannabinoids before their pregnancy continued to do so during the course of the pregnancy.

Linear regression analysis was performed to determine the factors that were predictive of the use of tobacco in the current pregnancy. This analysis involved the education level of the patients, whether or not alcohol and tobacco use had occurred throughout their lifetime, and the use of these substances in previous pregnancies. The results showed that

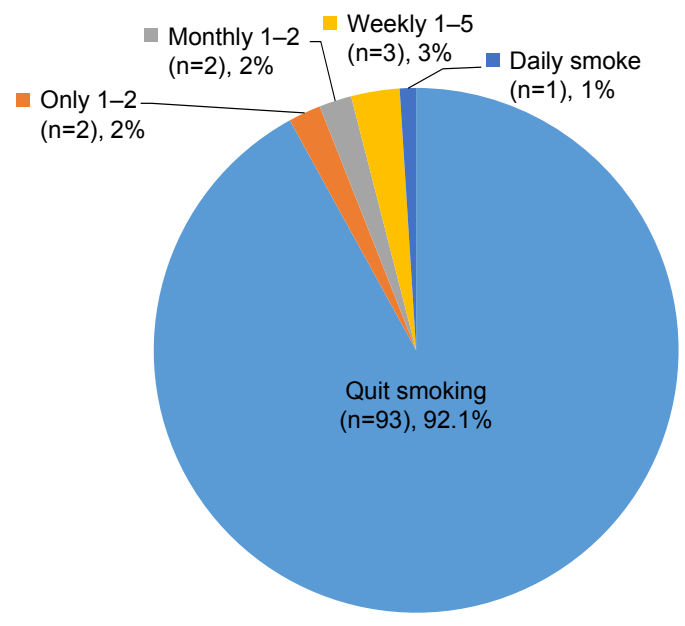

Figure 2 Quitting rates of other smokers during pregnancy.
Table 2 Predictors of the use of tobacco and alcohol during pregnancy

\begin{tabular}{llll}
\hline & Beta & $\boldsymbol{t}$ & $\boldsymbol{p}$-value \\
\hline $\begin{array}{l}\text { Predictors of the use of tobacco } \\
\text { (adjusted } \boldsymbol{R}^{2} \text { : } \mathbf{0 . 5 6 3 )}\end{array}$ & & & \\
$\begin{array}{l}\text { Education } \\
\text { Previous pregnancy tobacco use }\end{array}$ & 0.022 & 0.862 & 0.389 \\
Lifelong tobacco use & 0.234 & 19,522 & 0.000 \\
Alcohol use in previous pregnancy & -0.032 & -1.008 & 0.000 \\
Lifelong alcohol use & 0.036 & 1.113 & 0.314 \\
Predictors of the use of alcohol & & & \\
(adjusted $\boldsymbol{R}^{2}$ : 0.872) & & & \\
Education & -0.021 & -1.486 & 0.138 \\
Alcohol use in previous pregnancies & 0.978 & 57,058 & 0.000 \\
Lifelong alcohol use & -0.087 & -4.930 & 0.000 \\
Lifelong tobacco use & 0.025 & 1.520 & 0.129 \\
Tobacco use in previous pregnancies & -0.052 & -3.154 & 0.002 \\
\hline
\end{tabular}

while lifelong tobacco use and its use in previous pregnancies was a positive predictor of the use of tobacco in the current pregnancy, a significant correlation between education level and the use of alcohol was not observed (Table 2).

The same analysis was applied to gauge the factors that were predictive of the use of alcohol in the current pregnancy, using the same components as those included for tobacco (education level of the patients, whether or not the alcohol and tobacco use had occurred throughout their lifetime, and the use of these substances in previous pregnancies). Again, while the use of alcohol and cigarettes in previous pregnancies was found to be a positive predictor of the use of alcohol in the current pregnancy, a significant relationship between education level, the lifelong use of cigarettes, and the use of alcohol in the current pregnancy was not observed (Table 2).

\section{Discussion}

Rates of alcohol and substance use are known to be lower in females than in males. ${ }^{1,2}$ Only a limited number of studies have been published on the frequency of substance use during pregnancy in Turkey. ${ }^{15,23,24}$ In the current study, the substances used by pregnant females were investigated using a self-report scale, according to which the use of tobacco, alcohol, synthetic cannabinoids, and various other drugs was assessed.

\section{Smoking}

Thirty-four percent of the participants in this study reported that they had smoked cigarettes or other tobacco products at least once in their lifetime and $23 \%$ reported smoking every day prior to their pregnancy. Based on TSI health research 
data from 2012, in which the findings of various studies conducted in a number of cities at different times were amalgamated, $10.8 \%$ of Turkish females smoked every day and $12.7 \%$ had smoked at least once. ${ }^{14}$ The smoking rate in this study was found to be higher than the national average. However, both lower and higher rates, by comparison, have been reported in regional studies on females. ${ }^{25,26}$

In this study, $11.1 \%$ of the females who had had multiparas reported that they had smoked cigarettes or other tobacco products at least once, $7.5 \%$ stated that they had smoked every day during their previous pregnancies, $11.8 \%$ of the currently pregnant participants said that they had smoked at least once, and $6.4 \%$ admitted to doing so every day. This shows that there was a significant decrease in the incidence of smoking during pregnancy for both daily and other smokers. However, $42.5 \%$ of the females who smoked daily and $7.9 \%$ of the other smokers continued to do so throughout their pregnancy. These data show that a significant number of females who smoke daily are not able to quit smoking easily, even when pregnant.

The findings of a study conducted on 205 pregnant females in Sakarya Province, Turkey, in 2006 were similar to those of this study; $20 \%$ of the females smoked at least once a day when not pregnant and $62.5 \%$ of smokers did not quit during their pregnancy. Similarly, it was shown in this study that the incidence of smoking was reduced during pregnancy, but that a significant number of pregnant females continued to smoke. The smoking rate was reported to be $17 \%$ at any time during pregnancy in another study from Turkey, while the proportion of females who smoked during their entire pregnancy was $9 \% .{ }^{26}$

The rates of smoking by pregnant females differ between countries. It was reported in a nationwide Japanese study that $9.9 \%$ of pregnant females smoked and $38.1 \%$ continued to do so during pregnancy ${ }^{27}$ Elsewhere, it was reported in a study in Australia that $17 \%$ of pregnant females smoked during pregnancy and that only $4 \%$ quit when pregnant. ${ }^{28}$ It was reported in a study conducted in Greece that $48 \%$ of females use tobacco in the first trimester of pregnancy. Of the tobacco users, $83.3 \%$ reported attempting to quit, but less than half (45.1\%) were successful. ${ }^{20}$ It was also shown in a study from Russia that $25.2 \%$ of mothers were smokers before their pregnancy and that $18.9 \%$ continued to smoke while pregnant. ${ }^{29}$

The results of this study are congruent with those of previous studies. ${ }^{20,27-29}$ Thus, the need to screen for substance use and smoking during pregnancy is emphasized. It is harder for females who smoked on a daily basis prior to their pregnancy to quit smoking once pregnant.

\section{Alcohol}

The rate of lifelong alcohol use in this study was found to be $3.9 \%$, and $0.6 \%$ and $0.4 \%$ for previous pregnancies and the current pregnancy, respectively. There was a clear reduction in alcohol use during pregnancy, but remarkably, females who still drank alcohol during their pregnancy did so every day. Based on countrywide data collected by the TSI in 2012, 3.8\% of females drank alcohol regularly, and $92 \%$ had never consumed alcohol. ${ }^{14}$ The alcoholic drinking rate for females was found to be higher than that for general society in research conducted on Turkish youth, with a reduction in intersex difference. Particular attention should be paid to alcohol consumption in a young woman's life as it negatively impacts on her reproductive cycle and pregnancy. To the best of the authors' knowledge, the frequency of alcohol use during pregnancy has not been investigated in any study in Turkey prior to this study. The consumption of alcohol during pregnancy has been assessed in retrospective studies. ${ }^{30,31}$ Significantly, higher rates of alcohol consumption were reported in studies in which drinking prior to the discovery of the pregnancy was investigated, presumably because females who report alcohol use after the fact and outside of prenatal clinics are more truthful, and their information more reliable..$^{30,31}$

Rates of alcohol consumption in other countries vary, with a higher prevalence being reported in many European countries and Australia. For example, it was found in a French study that only $53 \%$ of females reported complete abstinence from the consumption of alcohol during pregnancy. ${ }^{32}$ Alcohol was consumed by $22.7 \%$ of pregnant females in a Spanish study, ${ }^{33} 24.6 \%$ of the females admitted to an antenatal clinic in Australia self-reported alcohol consumption during pregnancy, ${ }^{34}$ and $40 \%$ of females reported at least one episode of binge drinking since conception in a study in Denmark. ${ }^{34}$ Rates in other countries also vary considerably, with $57.4 \%$ of females in a prenatal clinic in Chile reporting alcohol consumption during pregnancy ${ }^{35}$ and rates of $46.7 \%$ and $59 \%$ being reported in relation to prenatal alcohol consumption in two Russian studies. ${ }^{36,37}$ It seems that alcohol consumption during pregnancy is generally lower in Turkey than it is elsewhere. The authors speculated that cultural factors, especially religion, may play an important role in this regard. Islam is the most predominant religion in Turkey. Accordingly, alcohol is forbidden. However, the high number of identified females who drink alcohol daily and who continue to do so during their pregnancy $(50 \%$ [Table 1]) suggests that a comprehensive investigation into substance addiction in females should be carried out during all routine polyclinic procedures. 


\section{Synthetic cannabinoids}

While only five females in this study reported using synthetic cannabinoids, two admitted to using these substances in their previous and current pregnancies. The Turkish National Police Department of Police Anti-smuggling and Organized Crime reported that the rate of illicit drug use on at least one occasion was $2.7 \%$. This rate was $3.1 \%$ in males and $2.2 \%$ in females. The prevalence of drug use was higher in young adults (aged 15-34 years) than that in the general population (aged 15-64 years). The prevalence of lifetime cannabis use was determined to be $0.7 \%$. This rate was $1.1 \%$ in males and $0.2 \%$ in females. Most (95.2\%) deaths directly relating to drugs were male victims, with only $4.8 \%$ of these being females. These data show that drug use is more common in males. ${ }^{1}$ Although fewer females use illicit drugs, to do so during pregnancy increases the health risks in both the mother and infant. In this study, synthetic cannabinoid users tended to maintain the use of synthetic cannabinoids during pregnancy and thus were identified as a group in particular need of guidance and counseling.

\section{Other drugs and inhalants}

In this study, only one female reported using biperiden, alprazolam, and similar drugs outside her pregnancy. Other drugs were not used during pregnancy in this study, but in a study that was conducted in Sivas, Turkey, the rate of volatile substance use (lifelong at least once) was found to be $16.3 \%$ in females and $9.3 \%$ in males, and that for cannabis was $1.6 \%$ in females and $2.1 \%$ in males. ${ }^{38}$ The use of inhalants in another study was determined to be $9 \%$ in males and $1 \%$ in females, and $8 \%$ in males and $7 \%$ in females for other drugs. ${ }^{26}$ Substance use was assessed in 1,082 pregnant females in Sakarya Province in this study, and none of the study participants reported the use of illicit substances, with the exception of synthetic cannabinoids, during their pregnancy. Although the results reflect low illicit substance and drug use, this study was of a limited size and was conducted on a specific sample. Thus, the results pertaining to illicit substance and drug use cannot be generalized to other pregnant females in Sakarya Province.

\section{Factors relating to substance use}

Smoking during previous pregnancies and over a lifetime was established to be prognostic of smoking during the most current pregnancy. This result is similar to those reported in previous studies. ${ }^{21,39}$ The fact that lifelong alcohol use and its use during a previous pregnancy is predictive of tobacco use in a current pregnancy can be explained by the co-occurrence of tobacco use in alcohol users. Both the lifelong use of alcohol and its use in previous pregnancies were determined to be prognostic of the use of alcohol in the current pregnancy. This result is also not surprising. ${ }^{40}$ Nevertheless, it emphasizes the idea that alcohol and substance use in prepregnancy should be investigated and should act as a "red flag" to their potential use in a future pregnancy. Smoking during pregnancy and lifelong smoking have been identified in numerous studies as being prognostic of alcohol use in the current pregnancy. ${ }^{40-43}$ Factors such as age, education level, number of pregnancies, and marital status were not determined to be prognosticators of alcohol or smoking use in this study. These variables have been reported as being predictors of substance use in some studies, but same results were not replicated/obtained in whole of the studies..$^{21,40}$ Further studies will help to determine certain risk factors for smoking, alcohol and substance abuse during pregnancy.

\section{Strengths and limitations of the study}

The main limitations of this study were that it was based on self-reports and that while the frequency of alcohol and substance use was investigated, the daily amount consumed was not. In addition, addiction levels with respect to smoking and drinking were not determined through the use of a scale or clinical interviews. Sakarya Province is a main metropolitan area in Turkey, but the modernization process in this area is not yet complete. The stigmatization of society for participating in such studies is a considerable obstacle.

The identities of this study participants were kept anonymous so that they were free to respond truthfully. This may explain the high rates of smoking, alcohol, and substance abuse identified in this study. The authors think that this was a key strength of this study. Additionally, this is the first study of its kind to be carried out in Turkey and the findings have been published in English on Google Scholar, PubMed, and Medline.

\section{Conclusion}

Cigarettes are the most frequently used substance in pregnancy and quitting rates are low. Alcohol and synthetic cannabinoids are also risky substances whose use has been reported in pregnancy. It is recommended that physicians sensitively enquire about all forms of substance use in pregnant females admitted to clinics and specifically about smoking, alcohol, and synthetic cannabinoid usage. These questions should also be included in routine enquiries. 
A need for similar studies to be conducted nationwide, and for pregnant females to be monitored methodically with respect to smoking, alcohol, and substance use, was identified in this study.

\section{Acknowledgments}

The authors are grateful to the staff in the Obstetrics and Gynaecology Department, Faculty of Medicine, Sakarya University, Turkey, and in particular, Nevin Bora, for her contribution to the follow-up of data in this study and for communicating with the participants. An abstract of this paper was presented in poster format at the 8th International Congress on Psychopharmacology \& 4th International Symposium on Child and Adolescent Psychopharmacology and was published in the "Klinik Psikofarmakoloji Bulteni (Bulletin of Clinical Psychopharmacology)" in 2016 (Volume 26, Supplement 1, dated 1 April).

\section{Disclosure}

The authors report no conflicts of interest in this work.

\section{References}

1. TUBIM. Turkish National Police Anti-smuggling and Organized Crime Department, National Report (2012 Data) Turkish Monitoring Centre for Drugs and Drug Addiction (TUBIM); 2013. Available from: http:// www.emcdda.europa.eu/html.cfm/index228535EN.html. Accessed May 16, 2014.

2. UNODC. United Nations Office on Drugs and Crime, World Drug Report United Nations publication, Sales No. E.14.XI.7; 2014. Available from: www.unodc.org/documents/wdr2014/World_Drug_Report_2014_web. pdf. Accessed December 4, 2015.

3. EMCDDA. European Monitoring Centre for Drugs and Drug Addiction, European drug report: trends and developments Luxembourg: Office for Official Publications of the European Communities; 2013. Available from: http://www.emcdda.europa.eu/attachements.cfm/ att_213154_EN_TDAT13001ENN1.pdf. Accessed December 7, 2015 .

4. Hacihasanoglu R, Türkles S, Yildirim A, Karakurt P. Lise Öğrencilerinde Madde Bağımlılı̆̆ 1 ve Etkileyen Faktörlerin İncelenmesi. [A research of drug addiction and influential factors in high school students]. Bagimlilik Dergisi. 2009;10(3):111-123. Turkish.

5. Ogel K, Corapcioglu A, Şenel Tot $S$, et al. Türkiye'de Ortaöğretim Gençliği Arasında Ecstasy Kullanımı [Ecstasy use in secondary school students in Turkey]. Bagimlilik Dergisi. 2003;4(2):67-71. Turkish.

6. Chou SP, Dawson DA. A study of the gender differences in morbidity among individuals diagnosed with alcohol abuse and/or dependence. $J$ Subst Abuse. 1994;6(4):381-392.

7. Compton WM, Thomas YF, Conway KP, Colliver JD. Developments in the epidemiology of drug use and drug use disorders. Am J Psychiatry. 2005;162(8):1494-1502.

8. NSDUH. Substance Abuse and Mental Health Services Administration, Results from the 2013 National Survey on Drug Use and Health: Summary of National Findings, NSDUH Series H-48, HHS Publication No (SMA) 14-4863. Rockville, MD: Substance Abuse and Mental Health Services Administration; 2014.

9. Caetano R, Schafer J, Cunradi CB. Alcohol-related intimate partner violence among white, black, and Hispanic couples in the United States. Alcohol Res Health. 2001;25(1):58-65.
10. Finnegan L. Substance Abuse in Canada: Licit and Illicit Drug Use during Pregnancy: Maternal, Neonatal and Early Childhood Consequences. Ottawa: Canadian Centre on Substance Abuse; 2013. Available from: http://www.ccsa.ca/Resource\%20Library/CCSA-Drug-Use-duringPregnancy-Report-2013-en.pdf. Accessed December 12, 2015.

11. NSDUH. Substance Abuse and Mental Health Services Administration. Results from the 2007 National Survey on Drug Use and Health: National Findings Office of Applied Studies, NSDUH Series H-34, DHHS Publication No. SMA 08-4343. Rockville, MD: SAMHSA; 2008.

12. Ebrahim SH, Gfroerer J. Pregnancy-related substance use in the United States during 1996-1998. Obstet Gynecol. 2003;101(2): 374-379.

13. Forray A, Merry B, Lin H, Ruger JP, Yonkers KA. Perinatal substance use: a prospective evaluation of abstinence and relapse. Drug Alcohol Depend. 2015;150:147-155.

14. Turkish Statistical Institute (TUIK). Health Survey 2012. Ankara: Turkish Statistical Institute, Printing Division; 2013.

15. Izci F, Bilici R. Gebelerde Madde Kullanımı: Görülme Sıklığı ve Etkileri. [Substance use among pregnant women: frequency and effects]. Bagimlilik Dergisi. 2015;16(1):26-34. Turkish.

16. Salihu HM, Wilson RE. Epidemiology of prenatal smoking and perinatal outcomes. Early Human Develop. 2007;83(11):713-720.

17. Hankin JR. Fetal alcohol syndrome prevention research. Alcohol Res Health. 2002;26(1):58-65.

18. Dow K, Ordean A, Murphy-Oikonen J, et al; Neonatal Abstinence Syndrome Work Group. Neonatal abstinence syndrome clinical practice guidelines for Ontario. J Popul Ther Clin Pharmacol. 2012;19(3): e488-e506.

19. Day NL, Leech SL, Goldschmidt L. The effects of prenatal marijuana exposure on delinquent behaviors are mediated by measures of neurocognitive functioning. Neurotoxicol Teratol. 2011;33(1): $129-136$.

20. Vivilaki VG, Diamanti A, Tzeli M, et al. Exposure to active and passive smoking among Greek pregnant women. Tob Induc Dis. 2016; $14: 12$.

21. Schneider S, Huy C, Schutz J, Diehl K. Smoking cessation during pregnancy: a systematic literature review. Drug Alcohol Rev. 2010; 29(1):81-90.

22. Ogel K, Evren C, Karadag F, Gurol DT. Bağımlılık Profil İndeksi’nin (BAPI) Geliştirilmesi, Geçerlik ve Güvenilirliği [The development, validity, and reliability of the Addiction Profile Index (API)]. Turk psikiyatri dergisi. 2012;23(4):263-275. Turkish.

23. Kocak C, Kurcer M, Arikan II. Bulent Ecevit Universitesi Hastanesi Gebe Poliklinigine Başvuran Kadınların Sigara Içme Konusunda Bilgi, Tutum ve Davranısları [Knowledge, Attitudes, and Behaviors of Pregnant Women Regarding Smoking Who Were Admitted to the Obstetrics Clinic of the Bulent Ecevit University Hospital.] Istanbul Medical Journal. 2015;16:133-136. Turkish.

24. Kucur R, Cilli AS, Aşkın R, Herken H, Kaya N, Özkan I. Konya'da üniversite öğrencilerinde CIDI/DSM-IV Ruhsal Bozukluklarının 12 aylık yaygınlığı. Selçuk Üniversitesi Tıp Fakültesi Araştırma Projesi. [12 monthly prevalence of CIDI/ DSM-IV mental disorders among university students in Konya. Research Project of Selcuk University Faculty of Medicine]. Konya/Turkey. 2000:7-8. Turkish.

25. Tot Ş, Yazıcı K, Yazıcı A, Metin Ö, Bal N, Erdem P. Psychosocial correlates of substance use among adolescents in Mersin, Turkey. Public Health. 2004;118(8):588-593.

26. Marakoglu K, Sezer R. Sivasta gebelikte sigara kullanımı [Smoking in pregnancy in Sivas]. Cumhuriyet Üniversitesi Tip Fakültesi. 2003; 25(4):157-164. Turkish.

27. Kaneita Y, Tomofumi S, Takemura S, et al. Prevalence of smoking and associated factors among pregnant women in Japan. Prev Med. 2007; 45(1):15-20.

28. Mohsin M, Bauman AE. Socio-demographic factors associated with smoking and smoking cessation among 426,344 pregnant women in New South Wales, Australia. BMC Public Health. 2005;5:138. 
29. Kharkova OA, Krettek A, Grjibovski AM, Nieboer E, Odland JO. Prevalence of smoking before and during pregnancy and changes in this habit during pregnancy in Northwest Russia: a Murmansk county birth registry study. Reprod Health. 2016;13:18.

30. Alvik A, Haldorsen T, Groholt B, Lindemann R. Alcohol consumption before and during pregnancy comparing concurrent and retrospective reports. Alcohol Clin Exp Res. 2006;30(3):510-515.

31. Hannigan JH, Chiodo LM, Sokol RJ, et al. A 14-year retrospective maternal report of alcohol consumption in pregnancy predicts pregnancy and teen outcomes. Alcohol. 2010;44(7-8):583-594.

32. Malet L, de Chazeron I, Llorca PM, Lemery D. Alcohol consumption during pregnancy: a urge to increase prevention and screening. Eur $J$ Epidemiol. 2006;21(10):787-788.

33. Palma S, Pardo-Crespo R, Mariscal M, Perez-Iglesias R, Llorca J, Delgado-Rodriguez M. Weekday but not weekend alcohol consumption before pregnancy influences alcohol cessation during pregnancy. Eur J Public Health. 2007;17(4):394-399.

34. Rimmer C, de Costa C. A retrospective review of self-reported alcohol intake among women attending for antenatal care in Far North Queensland. Aust N Z J Obstet Gynaecol. 2006;46(3):229-233.

35. Aros S, Mills JL, Torres C, et al. Prospective identification of pregnant women drinking four or more standard drinks ( $>$ or $=48 \mathrm{~g}$ ) of alcohol per day. Subst Use Misuse. 2006;41(2):183-197.

36. Chambers CD, Kavteladze L, Joutchenko L, Bakhireva LN, Jones KL. Alcohol consumption patterns among pregnant women in the Moscow region of the Russian Federation. Alcohol. 2006;38(3):133-137.
37. Kristjanson AF, Wilsnack SC, Zvartau E, Tsoy M, Novikov B. Alcohol use in pregnant and nonpregnant Russian women. Alcohol Clin Exp Res. 2007;31(2):299-307.

38. Dogan O. Sivas ilindeki lise öğrencilerinde madde kullanım yaygınlığı. Bağımlılık Dergisi. [The Prevalence of Substance Use Among High School Students in Sivas]. 2001;2(2):53-56. Turkish.

39. Schneider S, Schutz J. Who smokes during pregnancy? A systematic literature review of population-based surveys conducted in developed countries between 1997 and 2006. Eur J Contracept Reprod Health Care. 2008;13(2):138-147.

40. Skagerstrom J, Chang G, Nilsen P. Predictors of drinking during pregnancy: a systematic review. J Womens Health (Larchmt). 2011;20(6): 901-913.

41. Hotham E, Ali R, White J, Robinson J. Pregnancy-related changes in tobacco, alcohol and cannabis use reported by antenatal patients at two public hospitals in South Australia. Aust N Z J Obstet Gynaecol. 2008; 48(3):248-254.

42. Passey ME, Sanson-Fisher RW, D’Este CA, Stirling JM. Tobacco, alcohol and cannabis use during pregnancy: clustering of risks. Drug Alcohol Depend. 2014;134:44-50.

43. Cnattingius S. The epidemiology of smoking during pregnancy: smoking prevalence, maternal characteristics, and pregnancy outcomes. Nicotine Tob Res. 2004;6(Supp1 2):S125-S140.
International Journal of Women's Health

\section{Publish your work in this journal}

The International Journal of Women's Health is an international, peerreviewed open-access journal publishing original research, reports, editorials, reviews and commentaries on all aspects of women's healthcare including gynecology, obstetrics, and breast cancer. The manuscript management system is completely online and includes

\section{Dovepress}

a very quick and fair peer-review system, which is all easy to use. Visit http://www.dovepress.com/testimonials.php to read real quotes from published authors. 